\title{
A Coerência do Sistema Jurídico em Luhmann: uma proposta ao fechamento operacional e à abertura cognitiva da decisão judicial
}

\author{
Luiz Henrique Urquhart Cademartori ${ }^{1}$ \\ Grazielly Alessandra Baggenstoss ${ }^{2}$
}

Resumo: No presente trabalho, propõe-se o exame das balizas da decisão judicial no atual Estado Constitucional de Direito a partir da teoria sistêmica de Niklas Luhmann, que destaca o Direito como subsistema social, motivo pelo que deve seguir os mecanismos de abertura cognitiva e fechamento operacional das estruturas sistêmicas, sob pena de corrupção de seus elementos, deficiências em sua reprodução e incapacidade de evolução autônoma e diferenciada. Possíveis métodos para a realização do Direito nas decisões judiciais são apresentados, atualmente, pelas teorias jurídicas garantista e neoconstitucionalista, que aqui são examinadas com o objetivo de se verificar prováveis correspondências de suas assertivas ao movimento de reprodução autônoma e de evolução do sistema teorizado por Luhmann e para que seja viável o delineamento de uma decisão judicial que se consubstancie, efetivamente, em uma operação comunicativa especial do sistema jurídico, sendo adequada para o fim a que se destina: (re)afirmação, concretização e especialização do sistema jurídico.

Palavras-chave: Teoria sistêmica de Niklas Luhman. Teorias jurídicas contemporâneas. Decisão judicial.
Abstract: In this work we propose to examine the goals of the judicial decision in the current Rule of Law Constitutional State using Niklas Luhmann's systemic theory, wich highlights law as social subsystem, and therefore it must follow that the cognitive mechanisms for opening and closing operations of systematic structures, under penalty of the corruption of its elements, of deficiencies in its reproduction and inability to self-evolve and differentiate. Possible methods to carry out the law in judicial decisions are produced, currently, by garantism and neo-constitutionalism legal theories, which are examined here in order to verify probable matches of their claims with the movement of reproduction and evolution of the autonomous system theorized by Luhmann and to make it feasible to design a court ruling that substantiates effectively in a communicative operation particular of the legal system, suitable for its intended purpose: (re)affirmation, achievement and expertise of the legal system.

Keywords: Luhmann's systemic theory. Contemporary law theories. Judicial decision.

1 Possui Pós-Doutorado em Filosofia do Direito pela Universidade de Granada (Espanha). Doutor em Direito do Estado e Mestre em Instituições Jurídico-políticas pela Universidade Federal de Santa Catarina (UFSC). Professor da Universidade Federal de Santa Catarina (UFSC) nos cursos de Graduação e Pós-Graduação. E-mail: luiz.hc@terra.com.br.

2 Mestranda em Direito, Estado e Sociedade pela Universidade Federal de Santa Catarina (UFSC). Assessora Jurídica e Juíza Leiga pelo Tribunal de Justiça do Estado de Santa Catarina.E-mail: grazyab@gmail.com.

Recebido em: 23/03/2011.

Revisado em: 06/04/2011.

Aprovado em: 14/05/2011. 


\section{Introdução}

Ao teorizar sobre uma concepção sistêmica do fenômeno social, a partir da identificação de códigos binários que nela atuam, Niklas Luhmann destacou a comunicabilidade como elemento operacional por excelência e o código direito/não-direito como o binômio que identifica o sistema jurídico, no contexto do sistema social. Em seus elementos primordiais, constata-se a figura do órgão jurisdicional, como gerador das operações comunicativas de elevada importância deste sistema, que são as decisões judiciais.

Para a evolução do sistema jurídico e, por conseguinte, a sua correspondência com o meio em que se insere (sistema social), a sua referência interna deve obedecer ao mecanismo de fechamento operacional, que implica ausência de condicionamento do que ocorre no ambiente. E de outra parte, ao mecanismo de abertura cognitiva, que estabelece que a inserção de um elemento cognitivo do ambiente pauta-se na seleção daquele que é tolerado pela estrutura do sistema, que já o percebeu a priori como uma das probabilidades atuantes no movimento sistêmico.

A Constituição, por consequência, manifesta-se como acoplamento estrutural e determina o comportamento dos órgãos jurisdicionais e, por isso, os limites de conteúdo das decisões produzidas pelo sistema, visto que a interferência no subsistema Direito opera com a decisão judicial, desde que sua formação conte com elementos previstos e suportados pelo sistema.

Na contemporaneidade, todavia, observa-se a tendência de adoção de códigos de outros subsistemas em tais decisões, o que provoca a inserção de elementos não jurídicos no sistema e o impede de se reproduzir autonomamente e de evoluir estruturalmente. Os efeitos dessa miscelânea são a degradação da robustez dos códigos constitucionais e legais nas preferências particulares/pessoais de quem tem a competência de produzir as decisões e, ainda, o bloqueio de outros critérios legítimos do sistema jurídico. Esse sistema, então, passa a sofrer o estancamento do processo concretizador da sua força normativa nos enunciados textuais. Deve-se superar, portanto, as condições desjuridicizantes que determinam a colonização do Direito por outros códigos oriundos de outros sistemas sociais. 
Por tais razões, intenta-se apresentar detidamente tal panorama teórico e esquematizar o contexto político-jurídico em que se inserem as decisões judiciais e, por fim, considerar uma possível solução para a alopoiese, a ser elucidada adiante, do sistema jurídico. Para tanto, se irá expor a proposta de duas teorias jurídicas bastante debatidas na atualidade: o Garantismo e o Neoconstitucionalismo, a fim de se deliberar sobre uma provável formatação coerente ${ }^{3}$ da decisão judicial e verificar em que medida, se possível, podem ambas ou alguma destas teorias, convergir com o modelo sistêmico da teoria de Luhmann.

\section{A Teoria Sistêmica de Niklas Luhmann: a inovação epistemo- lógica no estudo da sociedade}

Niklas Luhmann, com o objetivo de construir a Teoria da Sociedade, propôs uma teoria baseada no binômio sistema-ambiente, mais especificamente na distinção daquele, surgida nos limites impostos por este na análise de suas funcionalidades.

Ao se utilizar dos recentes avanços de diversas teorias, como a dos Sistemas, da Cibernética, da Evolução, da Comunicação, percebeu que a estruturação sistêmica dos fenômenos sociais integra uma evolução a qual denominou de funcional-estruturalismo, que considera o dinamismo presente no sistema e sua evolução por meio de perspectivas prováveis, já que as circunstâncias e contextos de interação no âmbito da sociedade são contingentes e indetermináveis. Assim, Luhmann suprime a subjetividade da explicação dos fenômenos sociais, haja vista a separação dos indivíduos humanos no dinamismo social.

O seu paradigma sistema-ambiente como recurso epistemológico da busca pela diferenciação de um componente do binômio representa o abandono do modelo tradicional do conceito de objeto, que se fundamenta nas propriedades daquilo que é pesquisado. Sua proposta caracteriza,

\footnotetext{
3 Adotou-se a acepção de coerência como a relação lógica interna entre os elementos de um sistema e, por conseguinte, de sua operacionalidade. In casu, trata-se da relação lógica havida entre elementos relacionais do sistema jurídico e das decisões judiciais advindas da estruturação sistêmica.
} 
de tal modo, a delimitação de um componente do binômio objeto-contexto a partir das diferenças verificadas na comparação entre esses elementos, eis que um é referencial do outro.

Seu ponto de partida é a noção de sistema como estrutura orientadora no tratamento do seu desnível de complexidade em relação ao ambiente $^{4}$. Assim, refere-se a um sistema autopoiético: aquele que autoproduz, autonomamente, suas estruturas e os elementos de sua composição, os quais, por sua vez, não existem fora do sistema e, ainda, são utilizados por este no estabelecimento de distinções ${ }^{5}$.

A rigor, pode-se dizer que, para aferir a conotação de autopoiese, é necessário considerar a inexistência de input ou output de elementos no sistema ou a partir dele, visto que é autônomo tanto no plano estrutural $^{6}$ quanto no plano operativo ${ }^{7}$. São, assim, sistemas fechados que se reproduzem a partir das operações que foram geradas antes, no próprio sistema ${ }^{8}$.

Como corolário disso tudo, o que não integra o sistema pertence ao ambiente: os elementos não peculiares do sistema participam do seu

4 NEVES, 2006. p. 59.

5 CADEMARTORI; DUARTE, 2009. p. 174.

6 O acoplamento estrutural designa quais são e como ocorrem as "dependências" do sistema em relação ao ambiente, ou seja, como essas "dependências" se compatibilizam com a autorreprodução do sistema. Isso não quer dizer que o ambiente determina as operações do sistema, ele apenas produz perturbações ou interferências ou, ainda, ruídos (sem qualquer pressuposto causal) que só são reconhecidas porque o próprio sistema processa essas informações com operações que lhe são próprias. (LUHMANN; DE GIORGI, 1994. p. 10 e 22).

7 No que tange às operações, sabe-se que sistemas autopoiéticos são estruturas que produzem não somente sua organização, mas também os elementos dos quais eles são compostos. Em um plano temporal, tais elementos são as operações. As operações, então, constituem os sistemas e não têm uma existência independente: eles são produzidos no sistema exatamente pelo fato de serem utilizados como distinções. São informações, distinções no próprio sistema, o que as caracteriza como unidades de uso para a produção de outras unidades de uso. A autopoiese refere-se, desse modo, ao nível operativo dos sistemas, indicando que eles são constituídos por elementos autoproduzidos (LUHMANN, 1997, p. 41).

8 CADEMARTORI; DUARTE, Op. Cit. p. 175. 
ambiente, dando-lhe a distinção necessária para sua configuração como estrutura sistêmica.

Tais elementos interagem entre si e produzem diversas operações. Quando o sistema não consegue responder imediatamente a todas as relações entre os elementos, e nem todas as suas possibilidades podem se realizar, desencadeia-se a complexidade do sistema ${ }^{9}$. Como o sistema gera probabilidades relacionais, torna-se mais complexo, mas em razão menor que o seu ambiente, cuja complexidade se revela sempre superior por conter um número maior de elementos gerando relações contingentes. Algumas relações se realizam, outras remanescem em potência.

Com as inúmeras possibilidades do ambiente, surgem várias outras, o que causa um aumento de desordem e contingência, e, por consequência, faz com que o sistema selecione apenas algumas possibilidades que lhe fazem sentido de acordo com a função que desempenham, tornando o ambiente menos complexo para ele. Se selecionasse todas, não sobreviveria ${ }^{10}$.

O sistema também é capaz de fixar seus próprios limites, ao diferenciar-se do ambiente, limitando as possibilidades no seu interior ${ }^{11}$.

Objetivando a organização de sua complexidade interna, o sistema se autodiferencia, visto ser condição essencial para esse enfrentamento de transformação interna, gerando assim, subsistemas, deixando de ser simples e tornando-se mais complexo. Por conseguinte, experimenta um processo de evolução, tal como aconteceu com o sistema Direito: diferenciou-se, primeiramente em público e privado. Depois, aquele se especializou em direito constitucional, administrativo, penal, dentre outros, o que revela sua crescente sofisticação (evolução) como subsistema ${ }^{12}$.

Essa evolução é condicionada às interferências/irritações do ambiente, que podem levá-lo à transformação de suas estruturas conforme a tolerância do sistema. Aqui, retoma-se a ideia de autopoiese: a produção de si mesmo, responsável por um aumento constante de possibilidades até

9 KUNZLER, 2004. p. 124-125.

${ }^{10}$ Ibid, p. 125.

11 Ibid, p. 125.

12 Ibid, p. 125. 
que a complexidade atinja limites não tolerados pela estrutura do sistema, leva-o a mudar sua forma de diferenciação. A evolução do sistema ocorre quando ele se autodiferencia e ainda quando há uma passagem de um tipo de diferenciação para outro.

O ambiente pode interferir no sistema e provocar sua autoprodução, pois se trata de um estímulo à sua autopoiese. A esse respeito, Kunzler explana que as "irritações [ou interferências] se dão sempre e inicialmente a partir de diferenciações e comparações com estruturas (expectativas) internas aos sistemas, sendo, portanto, - do mesmo modo que a informação - necessariamente produto do sistema" ${ }^{13}$. Algumas possibilidades do ambiente irão chamar a atenção do sistema, nele causando interferências.

É nessa conjuntura que o sistema evolui com o objetivo de sobreviver à complexidade criada com as contingências inesperadas do seu meio, impulsionando-o a uma reforma, que não pode ser planejada, visto que ela se nutre dos desvios da reprodução normal.

Merece destaque, por oportuno, o fechamento operacional do sistema; a sua abertura cognitiva; e a sua comunicabilidade.

O fechamento operacional significa que nem o ambiente nem o sistema podem agir na esfera de operacionalidade, um do outro. No caso do sistema, é de sua operação interna a observação, a irritação, a seleção e a informação, inexistindo inputs ou outputs, como citado, não importando elementos prontos e acabados do ambiente.

Se o sistema selecionar um elemento do ambiente, será assimilado pela sua estrutura de acordo com a função que possa desempenhar. Isso porque o sistema não poderia construir sua própria identidade/complexidade e seu próprio conhecimento se fosse confundido com o ambiente/ meio $^{14}$.

\footnotetext{
13 Ibid, p. 128.

14 Se a estrutura sistêmica verifica um elemento no ambiente, está diferenciando algo no meio do caos, no meio do indiferenciado. O conhecimento projeta diferenciações numa realidade, que não conhece nenhuma diferenciação, pois conhecer é caracterizar algo como é e não como não é - mas é desta designação que surge a distinção caracterizadora. Os demais elementos não designados permanecem no ambiente.
} 
Esse fechamento favorece o autoaperfeiçoamento da complexidade do sistema e, quanto mais complexo, mais apto está ao conhecimento do ambiente porque, sob a condição de fechamento, o sistema desenvolve a própria complexidade e aumenta, com isso, suas realizações cognitivas.

O fechamento operacional é, por isso, condição para o conhecimento e somente o é porque o sistema não pode estabelecer nenhum contato condicionante com o ambiente. Por não haver qualquer interferência do ambiente, o sistema gera conhecimento a partir da rede recursiva das próprias operações.

Assim, o que não faz sentido para o sistema é descartado e resta na complexidade do ambiente como força potencial a ser utilizada em momento posterior, se oportuno - razão pela qual se pode afirmar que, no lugar de limites territoriais ou materiais, o sistema tem limites de sentido ${ }^{15}$.

A Teoria dos Sistemas, por isso, permite identificar o meio social como sendo um sistema e o ser humano, como o ambiente desse sistema. Isso leva à conclusão de que o social não surge do homem porque, para a teoria de Luhmann, a sociedade é a resposta evolutiva que antecede os sujeitos e se direciona a prover estruturas de sentido, numa dinâmica autorreferida. Assim, a sociedade não seria uma construção feita à imagem e semelhança do ser humano, mas sim o resultado de uma prática evolutiva $^{16}$.

Para Luhmann, em outras palavras e por consequência, o sistema emergente no processo evolutivo social é o sistema de comunicação que se denomina sociedade. Daí se deduz que a sociedade e a comunicação partilham da mesma identidade. Assim, se o sistema social é composto de comunicações, tudo o que não é ou que não é selecionado pelo sistema é ambiente - o que faz do ser humano, ambiente do sistema socia ${ }^{17}$.

Partindo do fundamento do que é sistema de comunicação, a sociedade abrange diferentes sistemas funcionais, distintos entre si por conta da diferenciação operacional: do ponto de vista da unidade, uma diferen-

${ }^{15}$ KUNZLER, Op. Cit., p. 128.

${ }^{16}$ CADEMARTORI; DUARTE, Op. Cit., p. 175.

17 Ibid, p. 175. 
ça verificada no sistema encontra-se em função do que o sistema diferenciou $^{18}$.

A comunicabilidade, além da existente entre os elementos de dentro do sistema, ainda se verifica com o exterior, o que Luhmann denomina de abertura cognitiva. Representa a demanda de conteúdo e de volume das relações havidas entre o sistema e o seu ambiente. Tais relações ocorrem em conformidade com a predisposição da estrutura sistêmica, ou seja, de acordo com sua capacidade de suportar interferências externas, conforme mencionado. Qualquer abertura do sistema só se justifica devido a seu fechamento, e isso se dá porque

[...] as operações autorreferenciais não absorvem o sentido global, não possuem um "efeito totalizante" mas, qualquer que sejam os fatores que concorrem para constituição do sistema (elementos, processos, o próprio sistema), são fenômenos não "puros", não referidos "somente e exclusivamente" a si, mas em grau de combinar autorreferenciabilidade e heterorreferenciabilidade ${ }^{19}$.

Disso, pontua-se que a comunicabilidade existente no sistema é autorreferente, ou interna, caracterizada pela abertura cognitiva, e é, também, heterorreferente, ou externa, observada no fechamento operacional.

Nesses termos, pode-se dizer que os sistemas sociais são sistemas abertos e fechados, e não abertos ou fechados, mas, paradoxalmente, são fechados porque são abertos ao meio ambiente a partir da comunicação. Assim como os pensamentos são gerados por um processo que implica novos pensamentos em uma rede organizada e lógica, a comunicação é o componente autopoiético dos sistemas sociais, pois uma comunicação fará nova comunicação de forma recursiva. Por isso, a comunicação é o único elemento que permite transcender a clausura do sistema.

18 LUHMANN; DE GIORGI, Op. Cit., p. 281.

19 FEBBRAJO, 1990. p. 13-14 e 24. 


\subsection{O Subsistema Jurídico e sua Autonomia como Distinção, Es- pecialização e Seletividade do Sistema Social}

Luhmann distingue três grandes sistemas sociais: os sistemas vivos (referentes às operações vitais), os sistemas psíquicos (afetos aos indivíduos), e os sistemas sociais (constituídos basicamente por comunicações).

Os sistemas sociais possuem dupla função: mediam a complexidade do mundo (ambiente) e a limitada capacidade do homem em assimilar as formas de vivência e buscam reduzir a complexidade, selecionando as possibilidades do mundo a partir de critérios internos ao sistema. Dentro dos sistemas sociais, têm-se subsistemas: economia, educação, direito, política, medicina - condição em que se vê a complexidade da sociedade moderna ${ }^{20}$.

Essa complexidade da sociedade moderna encerra a preocupação fundamental de Luhmann: o problema da ordem social. É sob tal égide que se assenta o subsistema Direito.

Para Luhmann, como o interesse da sociedade é a existência de comunicação, inexiste a ideia de um sujeito ou consciência coletiva e, por conseguinte, a possibilidade de um consenso fático entre os indivíduos como mecanismo de orientação social ou fundamento da sociedade. Isso porque, frente à seletividade da comunicação do sistema social, distinguiram-se os elementos que representavam a instituição das expectativas dos membros do seio social, porque

[...] o comportamento social em um mundo altamente complexo e contingente exige a realização de reduções que possibilitem expectativas comportamentais recíprocas e que são orientadas a partir das expectativas sobre tais expectativas ${ }^{21}$.

Como cada sistema só poderá ter conhecimento daquele setor que fica sob seu código particular e sua seletividade, a partir de um processo de diferenciação funcional e por sua evolução sociocultural, o Direito

\footnotetext{
20 MADEIRA, 2007, p. 27-29.

21 LUHMANN, 1983, p. 109.
} 
autonomizou-se da Moral até se constituir em um sistema social autopoiético, composto de comunicações de elementos normativos, cuja validade se remete de modo recursivo a outras expectativas normativas ${ }^{22}$.

A par disso, Luhmann assevera que o Direito, como expectativa das expectativas, cria:

[...] uma segurança [...] à qual se segue, apenas secundariamente, a segurança sobre o comportamento próprio e a previsibilidade do comportamento alheio. É muito importante, para a compreensão do direito, ter uma visão clara dessa diferença. Isso porque a segurança na expectativa sobre expectativas, seja ela alcançada por meio de estratégias puramente psíquicas ou por normas sociais, é uma base imprescindível de todas as interações, e muito mais importante que a segurança na satisfação de expectativas ${ }^{23}$.

A função do direito, portanto, é generalizar e estabilizar expectativas de condutas e regular conflitos mediante a constituição de procedimentos para fazê-lo. Nos termos de Amado:

[...] na própria estrutura de suas normas está implícita a previsão do conflito, pois sempre se coloca como alternativa de cumprimento e descumprimento. É o conflito precisamente, o descumprimento, o que exerce o efeito paradoxal de reforçar a expectativa normalizada, pois desencadeia os mecanismos tendentes à imposição contrafática dessa expectativa, que aparece assim reforçada perante os casos futuros. Daí que diga Luhmann que o direito usa a possibilidade de conflito para a generalização de expectativas (já que os conflitos são inevitáveis $)^{24}$.

Por tais razões, o direito não é um sistema meramente normativo, mas um alívio para as expectativas, que consiste na existência de caminhos generalizados em forma de uma eficiente indiferença inofensiva contra as outras possibilidades, que reduz consideravelmente o risco da

${ }^{22}$ MADEIRA, Op. Cit., p. 28-29.

${ }^{23}$ LUHMANN, 1983, p. 52-53.

${ }^{24}$ AMADO, 2004, p. 30. 
expectativa contrafática. Assim, a obtenção dos fins do Direito dá-se na sua eficiência seletiva acerca de expectativas comportamentais que possam ser generalizadas nas dimensões temporal, social e prática. É essa excelência na seletividade que é a variável evolutiva do Direito, pois é a reação às modificações do sistema social ao longo do desenvolvimento histórico. Por isso, o sistema jurídico é uma das bases necessárias para a evolução social ${ }^{25}$.

Considerando que o sistema em referência é autopoiético, todas as justificações operativas são dadas em seu interior e sua operatividade deve-se às operações de código binárias, que estabelecem a diferença entre o direito e o não-direito. Segundo Luhmann, não existem critérios de validade, nem reais nem hipotéticos do direito: o próprio direito é que se autoestabelece e se autolegitima internamente como normatividade jurídica. A positividade, portanto, não é mais que a referência autopoiética do sistema ${ }^{26}$.

Como as operações se reproduzem sem influência externa (a não ser pela assimilação seletiva de fatores do entorno, de acordo com os critérios do próprio sistema jurídico), o sistema jurídico estabiliza-se e sua validação dá-se recursivamente, por seus próprios códigos normativos. Nos termos de Neves e Samios, "o direito positivo reproduz-se de acordo com seus próprios critérios e códigos de preferência" 27 .

A codificação, dessa maneira, é essencial para que exista uma separação entre o direito e os aspectos morais ou políticos, visto ser a partir dos procedimentos eleitoral, legislativo e judicial do Estado de Direito que ocorre a filtragem e a imunização do sistema jurídico quanto às influências contraditórias do entorno - como a diversidade de expectativas, interesses e valores da sociedade moderna.

Em virtude disso, é possível um dissenso entre o Direito e outros valores e interesses. Essa possibilidade torna os procedimentos democráticos do Estado de Direito (que implicam o princípio da legalidade) uma

${ }^{25}$ LUHMANN, 1983, p. 115-116.

${ }^{26}$ NEVES; SAMIOS, 1997, p. 31.

${ }^{27}$ Ibid, p. 33. 
exigência sistêmico-funcional e uma imposição ética da sociedade complexa atual.

Para tanto, deve-se atentar para a possível porta de entrada de elementos não jurídicos: a abertura cognitiva (heterorreferência) em conjunto com o fechamento operacional (autorreferência) do sistema jurídico, sob o prisma da atual instituição do Estado Constitucional de Direito.

\subsubsection{Autorreferência e Heterorreferência do Sistema Jurídico no Estado Constitucional de Direito}

O Direito, autopoiético, autorreferente e fechado, por estar inserido em um sistema em escala macro, recebe interferências de outros subsistemas sociais, como o político, o econômico e o moral.

No caso do subsistema político, "devemos aceitar que a política somente participa no direito de maneira parasitária, e isso nos leva à questão de saber se e em que medida o sistema jurídico é capaz de regenerar o direito de forma autopoiética, e quando as influências jurídicas ganham relevo" 28 .

No que tange à interferência da economia, Luhmann afirma que:

Pela primeira vez todas as operações econômicas orientam-se no dinheiro. Todas as limitações do desejo, que estariam fundadas num sentido objetivo das coisas, encontram-se niveladas [...]. Não é possível apreciar como esta evolução é interpretada pelo direito. A história recente do direito mostra que a primeira reação consistiu numa grande generalização de certas instituições, sobretudo aquelas da propriedade e do contrato, como se fosse um caso de se reproduzir no interior do direito a mobilidade do dinheiro ${ }^{29}$.

Ora, sabe-se que os subsistemas citados interferem no sistema jurídico. Mas, para sua integridade, tal afetação deve ser de forma tolerante,

\footnotetext{
28 Ibid, p. 34.

${ }^{29}$ Ibid, p. 40.
} 
ou seja, interferir no sistema jurídico de modo que ele seja hábil a suportar sua interferência.

Neves, tratando da complexidade da sociedade moderna, aponta que a distinção entre modernidade central e periférica, causada pela desigualdade econômica no desenvolvimento entre Estados e regiões (com consequências significativas na reprodução de todos os subsistemas sociais, principalmente no político e no jurídico), e o desaparecimento de uma moral imediatamente válida para todas as esferas da sociedade impediram a criação de uma autonomia no sistema jurídico de acordo com o princípio da diferenciação funcional de uma esfera pública fundada na generalização institucional da cidadania ${ }^{30}$.

Assim, tem-se, como limite à abertura cognitiva ou à heterorreferência do sistema jurídico, o debate sobre juridificação versus desjuridificação. A questão que se estabelece, em conformidade com Neves e segundo o pensamento aqui adotado, é a dos limites da própria atividade estatal $^{31}$.

Em termos sistêmicos, a problemática refere-se à observação e à descrição dos efeitos da reprodução conjunta dos códigos "poder/não-poder" (em sentido amplo) e "lícito/ilícito" (ou direito/não-direito) no âmbito da organização estatal e em face dos demais subsistemas sociais. Nas palavras de Neves,

[...] aqui se trata da análise da autopoiese da política e do direito em face da autopoiese dos demais sistemas sociais. O debate dirigese, em princípio, à expansão da política e do direito em prejuízo da reprodução dos outros sistemas sociais. Mas, como cada sistema funcional apresenta-se como ambiente para os demais, não se lhes subordinando, a pretensão expansiva do Estado pode antes mostrar a incapacidade dos sistemas político e jurídico de observar adequadamente a autonomia do contexto ${ }^{32}$

30 NEVES, Op. Cit., p. 225-228, passim.

31 Ibid, p. 229.

32 Ibid, p. 231. 
Com a reprodução de outros subsistemas sociais dentro do político e, especialmente, no interior do sistema jurídico, a juridificação gera efeitos desintegradores das atividades estatais sobre a sociedade e reações desintegradoras sobre o Estado, já que o põe nos limites de sua própria capacidade funcional.

Sem a autonomia necessária para se gerir dentro do sistema jurídico, "[...] o Estado isola-se (paradoxalmente, porque se expande) sem suficiente amparo heterolegitimador. Torna-se difícil [...] reconhecer e processar o dissenso estrutural resultante da pluralidade de valores e de interesses" $" 33$.

A estatalização, que ocorre com a invasão do mundo (ambiente) da vida pelos sistemas político e jurídico, sofre fragilização da esfera pública, que é realimentada pelo desgaste do mundo da vida.

Contra a tendência à "juridificação" crescente, surge a estratégia de "desjuridificação", o que, de acordo com Neves, é uma ilusão. As propostas de resolução ou controle do problema dos efeitos disfuncionais da juridificação com decisões políticas subjazem a uma concepção instrumentalista do direito e voluntarista da política, que desconsidera a complexidade desses sistemas sociais na sociedade moderna, e que ainda sobrecarregam o Estado com novas atividades ${ }^{34}$.

É claro que a complexidade do sistema social exige o aumento dos encargos do Estado. Mas a mesma complexidade de uma sociedade diferenciada funcionalmente em sistemas autônomos importa a redução da capacidade regulatória do Direito. Neves alerta que

Não se trata de superar esse impasse, mas sim de conviver construtivamente com ele, fortificando a capacidade de aprendizado (abertura cognitiva) dos sistemas político e jurídico não apenas em relação aos demais sistemas sociais, mas também em relação aos influxos de informação que emergem criativamente da esfera pública pluralista e promovem a reciclagem do respectivo sistema ${ }^{35}$.

33 Ibid, p. 232-233.

34 Ibid, p. 233.

35 Ibid, p. 234. 
Por isso, a abertura cognitiva deve ser examinada a partir das competências constitucionalmente atribuídas aos órgãos jurisdicionais e à sua sobrecarga com questões estritamente políticas. Devem-se estabelecer quais as situações abusivas de intervenções desconstrutivas do Judiciário na formação democrática da vontade estatal e, ainda, quais as situações em que se verifica o excesso de invocação do Judiciário nos conflitos estritamente políticos em torno de decisões da maioria ${ }^{36}$ - o que dá azo ao exame do fechamento operacional do sistema jurídico.

Como cediço, de acordo com o modelo sistêmico luhmanniano, a sociedade moderna caracteriza-se pela hipercomplexidade, indissociavelmente vinculada à diferenciação funcional, que se realiza plenamente com a emergência de subsistemas autopoiéticos. Como inexiste uma reprodução autônoma dos sistemas jurídico e político, que sofrem interferências negativas de outros campos subsistêmicos, afasta-se a Constituição de sua função de acoplamento estrutural e como intermediação sistêmico-procedimental da esfera pública pluralista ${ }^{37}$.

Com isso, ante à hipercomplexidade social e à ausência de uma moral padrão à sociedade, não se alcançou a construção de sistemas sociais que apresentem autonomamente um topos específico. Segundo Neves,

Daí resultam problemas sociais bem [...] complicados [...]. As relações entre as esferas de comunicação assumem formas autodestrutivas e heterodestrutivas, com consequências desastrosas para a integração sistêmica e a inclusão social. Nesse sentido, a modernidade não se constrói positivamente, como superação da tradição por força do surgimento de sistemas funcionais autônomos, mas antes negativamente, como hipercomplexidade desagregadora do moralismo hierárquico tradicional ${ }^{38}$.

Diante disso, fala-se em alopoiese social do direito por força da prevalência de outros códigos de preferência sobre o código direito/nãodireito, já que não se vê uma definição clara das fronteiras de uma esfera

${ }^{36}$ Ibid, p. 235.

${ }^{37}$ Ibid, p. 236-237.

${ }^{38}$ Ibid, p. 238. 
de juridicidade, o que implica, fatidicamente, privilégios e exclusões ilegítimas.

Além da hipertrofia da preferência "ter/não-ter" (código econômico) atuar como óbice à reprodução sistêmica e autoconsistente do Direito e de sua ineficiência social, mecanismos relacionais, familiares, referentes à amizade e ao poder privatizado sobrepõem-se de forma difusa ao sistema jurídico, heteronimizando-lhe a reprodução operativa e corrompendo sua autonomia como estruturação sistêmica ${ }^{39}$.

As operações jurídicas do Estado Democrático de Direito, assim, são contaminadas por critérios extrajurídicos que, incontrolavelmente, corrompem o processamento de casos jurídicos de acordo com critérios generalizados de constitucionalidade e legalidade, concretizados jurisdicional e administrativamente.

Por tais razões, alerta Neves que "[...] é ingênua a interpretação de que se trata aqui de uma ampla abertura cognitiva do direito aos interesses sociais" ${ }^{40}$, já que, do ponto de vista sistêmico, abertura cognitiva pressupõe fechamento operacional ou normativo. Trata-se, em realidade, de quebra do fechamento operacional por onde se esfumaçam as fronteiras entre o sistema Direito e outras esferas de comunicação. Como corolário, o Direito sofre permanentes crises de identidade.

Esse quadro vem a ser denominado de corrupção sistêmica e tende à generalização em experiências jurídicas típicas da modernidade periférica, atingindo o próprio princípio da diferenciação funcional e resultando na alopoiese do direito ${ }^{41}$, em sentido inverso à especialização do sistema e, por conseguinte, obstando a sua evolução.

Como a concretização jurídica é violada por códigos de preferências os mais diversos, os códigos constitucionais e legais degradam-se em preferências particulares/pessoais e bloqueios oriundos de outros critérios sistêmicos, e têm seu desenvolvimento estancado no decorrer do processo concretizador de sentido, por conta da insuficiente força normativa dos

\footnotetext{
39 Ibid, p. 241-242.

40 Ibid, p. 240.

41 Ibid, p. 241.
} 
enunciados normativos. Daí se extrai que a questão central não está na produção de um maior ou menor volume de textos normativos: está na superação das condições desjuridicizantes que determinam a colonização do direito pelo sistema social ${ }^{42}$.

\subsubsection{Os Reflexos da Abertura Cognitiva e do Fechamento Ope- racional do Sistema Jurídico na Decisão Judicial e sua no Di- reito}

Na teoria dos sistemas sociais autopoiéticos aqui exposta, decisões são consideradas operações de indicação e distinção que efetivam uma interferência no sistema e, por isso, produzem também uma atualização dentro da dinâmica de seu fechamento operativo (autorreferência) e abertura cognitiva (heterorreferência) ${ }^{43}$.

Para o subsistema jurídico, relembra-se, a estruturação da comunicação ocorre pelo código da diferença entre direito e não-direito; a sua comunicabilidade parte de um sentido já estruturado simbolicamente pela estrutura sistêmica. Nas palavras de Simioni e Bahia:

Um evento qualquer da sociedade pode ser observado em termos de verdade e falsidade (código da ciência), como também pode ser observado em termos de pagamento ou não pagamento (código da economia) e igualmente pode ser observado em termos de governo ou oposição ao governo (código da política) ou entre informação nova e redundância (código dos meios de comunicação de massa), entre outros inúmeros contextos de significação possíveis. Mas, se esse evento for observado em termos de direito ou não direito, então já se está fazendo referência ao sistema jurídico da sociedade ${ }^{44}$.

No panorama apresentado, a decisão jurídica estabelece uma referência de comunicação à distinção entre direito e não-direito, ou seja, ao binômio Direito-ambiente. Por consequência, observa-se a produção de

\footnotetext{
42 Ibid, p. 241.

43 SIMIONI; BAHIA, 2009, p. 70.

44 Ibid, p. 70-71.
} 
decisões jurídicas em todos os contextos da sociedade, isso porque são jurídicas todas as decisões tomadas a partir do código da diferença entre direito e não-direito, independentemente do lugar onde elas acontecem ${ }^{45}$.

No entanto, tendo em vista que os sistemas sociais fechados operacionalmente são responsáveis pela produção da sua atualização, no subsistema do direito, o elemento estrutural que desempenha o papel do decidir jurídico (e de atualização do sistema) são os órgãos jurisdicionais, competentes e responsáveis pelas decisões judiciais. Estas se revelam como operações comunicativas especiais do sistema jurídico capazes, por sua coercibilidade e pela força interpretativa de seu conteúdo, de interferir intimamente na estrutura do sistema jurídico.

Como o sistema reproduz a si próprio através de operações recursivas-fechadas, produz também o sentido normativo a partir da base do elemento normativo. Não encontra sua qualidade normativa advinda de seu meio e tampouco pode fornecer tal qualidade ao seu ambiente: toda comunicação que se refere às normas jurídicas, nada mais é do que comunicação interna e própria do sistema.

$\mathrm{Na}$ análise operativa do subsistema Direito, importa acentuar que uma operação corriqueira comporta, simultaneamente, várias diferenças. Por isso, “[...] cuando se quiera saber cómo se observa una operación, se debe observar al observador [...]"46, porque o olhar de um observador também é uma operação que, igualmente, produz diferença. O pressuposto dessas diferenças é a distinção produzida pela operação de observação, ou seja, a distinção entre operação e observação ${ }^{47}$.

Toda observação é uma operação e produz uma interferência no sistema e, por isso, contribui para a sua autopoiese específica, representando uma reentrada da distinção naquilo que foi por ela mesma distinguido (paradoxo de re-entry into the form) ${ }^{48}$.

\footnotetext{
45 Ibid, p. 72.

46 LUHMANN, 2005. p. 106.

47 SIMIONI; BAHIA, Op. Cit., p. 75.

48 LUHMANN, 2007. p. 31.
} 
Uma re-entry é uma operação paradoxal que faz uso de duas distinções como se fosse uma só, mas não determina em qual dos lados da forma de distinção se reduplicará, deixando em aberto essa alternativa, produzindo uma ambivalência - o que leva à conclusão de que a operação de observação é sempre uma construção, que implica constatar se uma distinção é aceita ou negada nas subsequentes operações ${ }^{49}$.

Sobre tais termos, Luhmann defende, então, que a questão operacional do sistema jurídico não é exatamente como o juiz decide, mas sim como o sistema Direito produz as decisões na forma de operações de distinção dentro daquilo que já foi por ele mesmo diferenciado ${ }^{50}$.

Se é possível a reprodução redundante de uma operação, repete-se a decisão anterior; se inexiste tal possibilidade de repetição, tem-se a autêntica decisão jurídica: a introdução de uma operação distinta no sistema, o que acarreta interferência, afetando a redundância sistêmica e que, por conseguinte, pode culminar em transformações estruturais no sistema. Mas, repita-se, essa variação é tolerada ou selecionada pelas próprias estruturas e assimiladas como reestabilização.

Em consequência, a inovação produzida por uma decisão judicial constitui-se em referência para novas operações jurídicas se o seu sistema a aceitar/tolerar em suas estruturas. Isso significa que a decisão que inova sempre será uma decisão cuja probabilidade de ocorrência já fora prevista pelo sistema. Em outras palavras, sua inovação refere-se às operações anteriores, mas as potencialidades sempre são projetadas pelo sistema ${ }^{51}$.

Nesses termos, a teoria luhmanniana sugere que os casos singelos e/ ou de praxe (easy cases) são fundamentados no equacionamento de interesses do sistema, enquanto nos mais complexos (hard cases), verifica-se a autorreferência do sistema, ou seja, a referência aos casos já decididos. Cada decisão pode antecipar a direção de produção de outras decisões, da mesma forma com a qual o sistema utiliza essa prática estabelecida através de reiteradas decisões ${ }^{52}$.

\footnotetext{
49 Ibid, p. 34.

50 SIMIONI; BAHIA, Op. Cit., p. 76.

${ }^{51}$ Ibid, p. 78.

${ }^{52}$ MADEIRA, Op. Cit., p. 36.
} 
Conclui-se, assim, que o sistema jurídico comporta decisões apenas com a possibilidade de observação de tendências e as suas consequências determinadas a partir do que será decidido. A par disso, Luhmann ressalta que o direito fundamenta-se em um paradoxo: o direito positivo só tem validade na medida em que pode ser modificado através de uma decisão ${ }^{53}$.

Contudo, nas atuais condições de reprodução do subsistema jurídico, do sistema social e de uma sociedade moderna complexa e contingente, observa-se uma proliferação social de códigos e critérios, que torna indefinidas e confusas as fronteiras do campo jurídico e da esfera estatal perante outros âmbitos do agir e vivenciar, assim como as fronteiras do Direito e de suas estruturas prováveis ${ }^{54}$.

É o que se verifica nas decisões, cuja produção, a partir de sua escolha preferencial de probabilidade, considera fatores fundamentados em códigos de outros sistemas. Há, por conseguinte, a corrupção das decisões e, ainda, a corrupção do sistema jurídico por meio das decisões judiciais.

A questão é problemática e atual, conforme se vê no que se convencionou denominar de judicialização da política e também na repercussão geral como um problema de análise dos impactos especialmente econômicos da decisão jurídica. Simioni e Bahia exemplificam:

[...] um juiz que decide uma causa não porque a conduta do autor ou do réu foi correta ou incorreta do ponto de vista do direito, mas porque a decisão é lucrativa ou gera prejuízos econômicos, já tomou uma decisão econômica.

Assim, se um órgão jurisdicional "decide um fato fazendo política pública do governo ou da oposição, em detrimento à diferença entre direito e não direito, já tomou uma decisão política e não jurídica”. É desse tema que se extraem as posições teóricas que defendem a importância da argumentação jurídica para a justificação dessas decisões mais difíceis as que exigem um pouco mais do que respostas previstas no direito positivo $^{55}$.

53 Ibid, p. 34.

${ }^{54}$ LUHMANN, 2007, p. 34.

${ }^{55}$ SIMIONI; BAHIA, Op. Cit., p. 75-76. 
Neves alerta que "[...] enquanto se afasta de qualquer vínculo (fixado constitucionalmente) no código lícito/ilícito [...]", o sistema jurídico fica exposto "diretamente a particularismos relacionais e exigências econômicas concretas, não podendo, assim, reproduzir-se autonomamente"

Por isso, é inconcebível a abertura cognitiva do sistema jurídico para as exigências da economia e para os valores morais, as expectativas e os interesses presentes na esfera pública. O que deve existir é o seu fechamento operacional, que é um pressuposto sistêmico para seu devido conhecimento frente a um ambiente social altamente complexo ${ }^{57}$.

A decisão judicial, portanto, eis que operação comunicativa especial do sistema jurídico, deve espelhar a complexidade sistêmica e refletir a sua abertura cognitiva, de forma a manter a integridade do sistema (heterorreferência), e o seu fechamento operacional, sem que seus elementos se dissociem do sistema macro, que é o sistema social (autorreferência). De acordo com Luhmann,

O processo decisório da jurisprudência [entenda-se teoria do direito] não conhece [...] formas institucionalizadas de mudança do direito, mas apenas técnicas apócrifas de assimilação, adaptação ou alteração e que sejam compatíveis com a identidade formal das normas [...]. De resto, a inovação judicial é possível até mesmo frente à lei - mas só raramente e limitada a que durante algum tempo se trabalhe com argumentos falsos, até que a inovação seja introduzida [por via legislativa] e possa ser apresentada como direito antigo. Com isso o juiz, sob condições modificadas, dá continuidade àquelas colocações que antes eram genéricas e agora são apenas consideradas como uma possibilidade entre outras ${ }^{58}$.

A limitação do órgão jurisdicional é explicada pelo fato de ele lidar com situações em que já se verificaram frustrações. Esse elemento do sistema jurídico, portanto, trata do processamento de frustrações para o qual

${ }^{56}$ NEVES, Op. Cit., p. 243.

${ }^{57}$ Ibid, p. 242.

${ }^{58}$ LUHMANN, 1985. p. 36-37. 
se fazem essenciais um rígido referencial para as decisões e a manutenção das normas decisórias ${ }^{59}$.

Para tanto, faz-se imprescindível aos órgãos jurisdicionais um embasamento teórico que os instrumentalizem no manejo da dogmática jurídica, com vistas à realização do sistema Direito e ao favorecimento de sua estruturação autônoma, ainda mais em função de todas as novas demandas de direitos e as diversas polêmicas quanto ao tratamento dos diversos direitos fundamentais. Como respostas paradigmáticas a estes problemas, apontam-se em linhas gerais as duas teorias jurídicas mais discutidas contemporaneamente: a teoria jurídica garantista e a teoria jurídica neoconstitucionalista.

\section{As Propostas do Garantismo e do Neoconstitucionalismo para uma Teoria Jurídica do Estado Constitucional de Direito}

O Garantismo e o Neoconstitucionalismo podem ser tanto vinculados à Teoria do Direito, como à Teoria do Estado, ou ainda, à Filosofia Política e contrapõem-se, basicamente, nos mesmos moldes extremos em que se contrapõem os paradigmas do Positivismo Jurídico e o do Jusnaturalismo: vale dizer, a relação entre Direito e Moral.

Seu contexto atual, no entanto, é diverso de quando do levante da teoria positivista clássica: a teoria que se insurge e se assenta nos tribunais é o Neoconstitucionalismo, em resposta aos diversos relativismos existentes numa sociedade complexa e à inexistência de uma moral única convencional ${ }^{60}$, e contra esta se insurge o Garantismo.

\subsection{A Teoria Jurídica Garantista}

A Teoria do Garantismo aqui explanada é formulada por Luigi Ferrajoli, o qual, na obra Diritto e Ragione, em 1989, propõe um modelo

\footnotetext{
59 Ibid, p. 37.

60 Denominada por Habermas como sendo a moral conteudístico-hierárquica diretamente válida em todas as esferas do agir e do vivenciar (NEVES, Op. Cit., p. 237).
} 
ideal de Estado de Direito, em que se deve verificar a aproximação do direito positivo com o direito que realmente é observado no meio social, sob pena de deslegitimação ${ }^{61}$, reclamando a aproximação entre direito válido e direito efetivo.

Para tanto,

Ferrajoli observa que o Estado de Direito atual apresenta [...] certas inclinações neo-absolutistas, as quais se evidenciam por meio de práticas antigarantistas embasadas em normatividade de emergência e de exceção oriunda de interesses setoriais da sociedade, o que vem a enfraquecer o modelo de Estado de Direito entendido como artifício político a serviço do corpo social ${ }^{62}$.

Resultado de tais inclinações é a expansão das funções jurisdicionais e de seus espaços de discricionariedade, que buscam respaldo argumentativo nos setores social, econômico e político do Estado, a redução da capacidade regulativa do Direito, a inadequação e a falta de efetividade de suas técnicas de garantia e, ainda, a tendência do poder político a se libertar dos controles jurídicos e a sediar-se em áreas não institucionaliza$\operatorname{das}^{63}$.

São esses os motivos que impulsionaram a Teoria do Garantismo à construção de uma base filosófico-política constituída pela doutrina liberal da separação entre direito e moral. Suas principais teses, portanto, são:

a) a separação entre direito e moral, em que se diferencia a qualificação de uma norma como válida ou inválida (ao se analisar o direito internamente) e a qualificação de uma norma como justa ou injusta (se examinada pela perspectiva externa) ${ }^{64}$; sendo que

b) tal separação é tida a partir do postulado do filósofo empirista inglês, David Hume, que determina que não se pode deduzir prescrições de descrições, o que significa, entre outras coisas, que

\footnotetext{
61 CADEMARTORI, 1999, p. 92.

62 Ibid, p. 92.

63 Ibid, p. 92-93.

64 Ibid, p. 94.
} 
não se pode deduzir a moral do direito, visto que o direito válido não é por si um direito justo ${ }^{65}$. Separam-se, portanto, juízos de validade e juízos de valor.

Como teoria jurídica, então, o Garantismo sedia-se na forma jurídica do Estado atual, qual seja, a forma de Estado de Direito. Nessa acepção,

[...] designa una teoria jurídica de la "validez" y de la "efectividad" como categorías distintas no sólo entre sí, sino también respecto de la "existência" o "vigencia" de las normas. En este sentido, la palabra garantismo expresa una aproximación teórica que mantiene separados el "ser" y el "deber ser" en el derecho; e incluso propone, como cuestión teórica central la divergencia existente en los ordenamientos complejos entre modelos normativos (tendencialmente garantistas) y prácticas operativas (tendencialmente anti-garantistas), interpretándola mediante la antinomia - dentro de ciertos límites fisiológica y fuera de ellos patológica - que subsiste entre validez (e inefectividad) de los primeros y efectividad (e invalidez) de las segundas ${ }^{66}$.

Seu objetivo, por consequência, é uma crítica, não desconstrutiva, ao Direito positivo vigente, ou seja, uma crítica interna ao ordenamento jurídico posto e orientada a analisar os aspectos de sua ineficácia e invalidade, e não uma crítica externa, impedindo que a crítica parta de critérios políticos ou de justiça ${ }^{67}$.

\footnotetext{
65 Ibid, p. 94-95.

${ }^{66}$ FERRAJOLI, 2001, p. 852.

67 “O pano de fundo téorico-geral do garantismo está constituído em grande parte pela importante distinção entre quatro diferentes predicados que se podem imputar às normas: justiça, vigência, validade e eficácia (efetividade): a) uma norma é 'justa’ quando corresponde positivamente a determinado critério de valoração ético-político (logo, extrajurídico); b) uma norma é 'vigente' quando é despida de vícios formais; ou seja, foi emanada ou promulgada pelo sujeito ou órgão competente, de acordo com o procedimento prescrito; c) uma norma é 'válida' quando está imunizada contra vícios materiais; ou seja, não está em contradição com nenhuma norma hierarquicamente superior; d) uma norma é ‘eficaz' quando é de fato observada pelos seus destinatários (e/ou aplicada pelos órgãos de aplicação)" (CADEMARTORI, Op. Cit., p. 101-102).
} 
E a base de tal posicionamento é clara: o Estado Constitucional de Direito

[...] incorporou, em sua formação, diversos princípios ético-políticos a seus estatutos fundamentais, os quais determinam valorações ético-políticas e de justiça das normas por ele e nele produzidas, agindo como critérios de legitimidade ou ilegitimidade não mais externos ou jusnaturalistas, mas agora internos ou positivistas ${ }^{68}$.

A amplitude dos direitos considerados em sua forma natural, tais como princípios e valores, foram positivados como direitos fundamentais e devidamente limitados para sua adequação dentro do sistema normativo a fim de fortalecer o princípio da legalidade, que é o ponto de partida na construção do modelo garantista ${ }^{69}$.

Assim, de acordo com a Teoria Jurídica do Garantismo, pode-se afirmar que é inconcebível a perquirição acerca do consenso do Direito com a Justiça ou com a Política (o que representa o exame do sistema jurídico a partir de um ponto de vista externo), pois caracterizaria uma desconstrução do Estado de Direito. Tal tarefa, pois, cabe à filosofia político-jurídica.

Ferrajoli acredita que tais confusões advém das dúvidas acerca dos limites dos poderes Judiciário e Legislativo e de suas respectivas dimensões de discricionariedade. Assim, especificamente no tocante à produção e aplicação do Direito e aos questionamentos acerca dos espaços de discricionariedade, Ferrajoli sustenta que se deve estabelecer qual o conceito de discricionariedade própria do exercício de qualquer poder. Assim, a celeuma pode ser resolvida redimensionando-se o alcance da discricionariedade e pela análise de seus tipos. Diferencia e delimita, portanto, a discricionariedade política da discricionariedade judicial ${ }^{70}$.

A discricionariedade política contempla as funções governamentais e legislativas, cujo campo é o da política social. Em seus limites, a formação das leis representa a realização contínua e legítima das opções

\footnotetext{
${ }^{68}$ Ibid, p. 99.

${ }^{69}$ CARVALHO, 2001, p. 100-101.

${ }^{70}$ FERRAJOLI, 2006, p. 93.
} 
políticas sobre a prioridade que convém atribuir aos diferentes tipos de direitos. Adverte-se que seu âmbito de atuação não consiste em opções interpretativas, relativas aos significados dos direitos constitucionais estabelecidos, mas sim na determinação de normas novas, mais inovadoras e discricionárias que as opções que se produzem na aplicação constitucional ${ }^{71}$.

Portanto, é nessas possibilidades políticas, relativas a técnicas de garantia mais adequadas aos distintos tipos de direitos, às prioridades adotadas e à destinação de recursos, que reside o espaço autônomo da política.

Já a discricionariedade judicial caracteriza-se como atividade interpretativa e probatória da aplicação das normas legais ao objeto sub judice. É uma atividade tendencialmente cognoscitiva e dá-se com a sujeição à lei, estando limitada à interpretação das normas que poderão ser aplicadas. Assim, a sua fonte de legitimação não é a fonte político-representativa própria das instituições de governo, mas a sujeição à lei.

Ao espaço da jurisdição e da discricionariedade judicial pertencem só as controvérsias e decisões interpretativas referentes ao significado das leis passíveis de aplicação, o que, no entendimento de Ferrajoli, deveria ser suficiente para acabar com o fantasma do "governo dos juízes"72.

\subsection{A Teoria Neoconstitucionalista}

Diante da crise da legalidade frente à supremacia da Constituição e outros fenômenos mais ou menos conexos ao constitucionalismo advindos dessa crise (como a desconfiança do legislador), o Neoconstitucionalismo surge como resposta ao modelo de Estado de Direito descrito, oferecendo uma nova explicação e uma nova teoria do Direito, de acordo com esse abandono ao dogma da estatalidade e da legalidade do Direito ${ }^{73}$.

O Neoconstitucionalismo, portanto, apresenta diversas acepções para atingir tal objetivo, condizentes com seu conteúdo, limites e aplica-

\footnotetext{
71 Ibid, p. 94-95.

72 Ibid, p. 96-98, passim.

73 SANCHÍS, 2003, p. 123-124.
} 
ções. Sanchís, teórico dessa corrente, apresenta, objetivamente, três acepções de Neoconstitucionalismo: como um tipo de Estado de Direito; como uma teoria do Direito para explicar o modelo institucional de Estado; ou como ideologia que justifica ou defende a forma política mencionada. Como ideologia, ressaltam-se diferentes projeções: (a) como filosofia política, em que se considera o Estado Constitucional de Direito o melhor modelo ou a forma mais justa de organização política; (b) como método que defende a vinculação entre Direito e Moral; e (c) como constitucionalismo dogmático, por expor uma nova visão interpretativa do direito, da ciência e da teoria jurídicas (incluindo aqui, Dworkin, Habermas, Alexy e, contra sua vontade, Ferrajoli) $)^{74}$.

Para tanto, o autor propõe cinco epígrafes para a nova teoria: mais princípios que regras; mais ponderação do que subsunção normativa; onipresença da Constituição em todas as áreas jurídicas e em todos os conflitos minimamente relevantes; onipotência judicial no lugar da autonomia do legislador ordinário; e a coexistência de uma pluralidade de valores, por vezes tendencialmente contraditórios, em lugar da homogeneidade ideológica em torno de princípios coerentes entre si e em torno, principalmente, das sucessivas opções legislativas ${ }^{75}$.

Diante desse panorama, a base do Neoconstitucionalismo é firmada no equacionamento entre as dimensões do Direito, Moral e Política e de como se relacionam entre si, o que requer a aplicação de padrões de racionalidade, ou melhor, de razoabilidade prudencial no lugar da racionalidade oriunda do cientificismo formal, típico do positivismo jurídico ${ }^{76}$.

Em outros termos, é possível afirmar que, "em verdade, o Neoconstitucionalismo pretende ser uma teoria que se opõe às duas teses mais importantes do positivismo conceitual, ou seja, a tese das fontes sociais do direito e a não-conexão necessária entre o direito e a moral" ${ }^{17}$.

A primeira tese vale-se da identificação das fontes sociais do direito e a sua diferenciação dos outros sistemas normativos. Assim, a teoria das

\footnotetext{
${ }^{74}$ Ibid, p. 123-124.

75 Ibid, p. 131-132.

${ }^{76}$ CADEMARTORI; DUARTE, Op. Cit., p. 29.

77 Ibid, p. 41.
} 
fontes sociais do direito assinala os limites dele mesmo, ou seja, o Direito é considerado fato social e, portanto, seu núcleo reside nessas fontes sociais, que o determinam. Seus defensores afirmam que as decisões passadas determinam qual a resposta que deve ser dada em um determinado conflito jurídico e que, tratando-se de hard cases, o julgador pode ser um legislador intersticial ${ }^{78}$.

A segunda tese, qual seja a da separação do Direito face aos campos da Moral e da Política, pressupõe a autonomia entre o direito e sua justificação, ou seja, o direito é considerado em si, independente de ser justo ou injusto. Assim, pode-se dizer que "essa segunda tese é uma das mais discutidas por juristas como Dworkin, ao sustentar que a avaliação moral é necessária, tanto para entender como para descrever o Direito"79.

As teorias neoconstitucionalistas, dessa forma, interessam-se pelas questões que se referem à indeterminação do direito, além dos limites institucionalizados. Sob tal prisma, o operador do Direito e o juiz passam a ocupar o papel do legislador (embora seja possível, também no âmbito da teoria da legislação, o desenvolvimento de novas teorias da argumentação voltadas à fundamentação da lei a ser produzida) ${ }^{80}$.

Especificamente no que se refere ao relacionamento entre o Direito e a Moral, o Neoconstitucionalismo sustenta que, para o Positivismo Jurídico, o Direito não perde sua juridicidade pelo fato de ser injusto. $\mathrm{Ou}$ seja, uma coisa é o direito que é e outra, por certo diferente, é o direito que deve ser. Tais diferenciações são tipicamente positivistas. O Neoconstitucionalismo, por sua vez, apresenta tese em contrário. Isso porque, segundo esta corrente, a racionalidade moral desempenha um importante papel na formação do discurso de racionalidade jurídica e, em vista disso, existe uma relação intrínseca entre o Direito e a $\mathrm{Moral}^{81}$, e isto deve ser considerado na aplicação das normas jurídicas, a fim de se legitimar a discricionariedade dos órgãos jurisdicionais. Pelo que se observou destas duas teorias e pelo que será visto no tópico seguinte, resulta totalmen-

\footnotetext{
78 Ibid, p. 42.

79 Ibid, p. 42.

80 Ibid, p. 43.

${ }^{81}$ Ibid, p. 43-44.
} 
te incompatível com o modelo sistêmico luhmanniano, uma proposta tal como a desenvolvida pelo Neoconstitucionalismo, ao contrário do que possa ocorrer com a Teoria do Garantismo Jurídico.

\section{A Coerência do Sistema Jurídico Luhmanniano por meio da Formatação Recursiva da Decisão Judicial}

A função do Direito, como explanado, é generalizar e estabilizar expectativas dos comportamentos e promover a regulamentação dos conflitos, com a própria previsão do litígio em seu código (com a alternativa de cumprimento e descumprimento). É o conflito de interesses, precisamente, que desencadeia os mecanismos tendentes à imposição contrafática da expectativa regulatória. Assim, como os conflitos são inevitáveis, o Direito integra sua probabilidade para a generalização de expectativas.

Assim, o sistema jurídico realiza sua seletividade das expectativas comportamentais, o que é, repita-se, a variável evolutiva do Direito, pois representa a reação do sistema frente às interferências do sistema social ao longo do desenvolvimento histórico. Como corolário, o objetivo do Direito é o apaziguamento das expectativas sociais, garantindo a segurança jurídica com vistas à promoção da segurança social.

Contudo, a inserção de códigos alienígenas enfraquece a sua estrutura e, principalmente, o seu acoplamento estrutural (efetivado pela Constituição), pois, pelo fato de serem mais dinâmicos e mais representativos do meio social (refletindo o que é), acabam prevalecendo sobre o sistema jurídico - que ainda determina e coage o que deve ser, sob uma conotação kelseniana. Isso representa uma tolerância à beira da insustentabilidade devido ao impedimento de sua evolução (com as referências a si mesmo) e com consequente regressão.

Vê-se que tais códigos heterogêneos e, por vezes, contraditórios perseguem tendências setoriais, ideologias políticas, particularismos individuais, flutuações econômicas. Por isso, considerando a inexistência de uma moral convencional e a atuação de relativismos axiológicos frente a relações semelhantes, mas em contextos diversos (o que culmina na complexidade social), tem-se questões-chave para a busca da coerência 
do sistema jurídico: a) Inexistindo moral única no âmbito da complexidade social, como vinculá-la ao Direito? b) Tendo em vista a variação da ideologia conforme a dimensão tempo-espaço e em função da corrente de pensamento abraçada, é possível a Política servir de base ao Direito? c) Como o manejo do mercado é realizado por aqueles que detêm maior número de propriedades privadas e propriedades produtivas; como embasar o Direito no critério econômico?

Frente às ponderações feitas a esses questionamentos no decorrer deste trabalho, conclui-se que é inconcebível o entranhamento da instabilidade flutuante dos critérios econômico e político e do relativismo sociopolítico, no sistema jurídico, o que vale também para propostas tais como as derivadas do Neoconstitucionalismo, ao pretender a reaproximação entre esferas tais como o Direito, a Moral e a Política.

Com isso, o caminho proposto para o fortalecimento do Direito é o de respeito à sua abertura cognitiva e ao seu fechamento operacional. Como a abertura cognitiva representa a demanda de relações havidas entre o sistema e o seu ambiente, de acordo com a sua capacidade de suportar interferências externas, o sistema deve conhecer o que é tolerado, que é o que está contido no código do direito, ou seja, nas normas consolidadas pelo princípio da legalidade. O fechamento operacional, então, deve representar a não interferência do ambiente na esfera de operacionalidade do sistema e impedir a importação de elementos prontos e acabados do ambiente. O objetivo é manter a estrutura não corrompida, mantendo a autonomia do sistema jurídico para sua reprodução evolutiva e especializada.

Além disso, deve-se identificar os elementos presentes no discurso jurídico que não participam do binômio direito/não-direito e, por fim, expurgar da estrutura sistêmica tais códigos sociais alienígenas, tais como os critérios econômicos baseados no código ter/não-ter; os políticos, no binômio poder/não-poder, e os morais, traduzindo preferências subjetivas passíveis de gradação, para a aceitação individual e social.

Em suma, dessa maneira, vale dizer, preservando a especificidade do código operacional do sistema jurídico, alcança-se a incolumidade do sistema, desde que sua operacionalidade siga a abertura do que lhe é afeto e tolerado, o que implica o fechamento para sua autorreferência e, 
acrescente-se, a distinção e a eliminação dos elementos que pertençam a códigos externos. Isto deve ocorrer especialmente nas operações por excelência do sistema jurídico, que são as decisões judiciais, que produzem a (re)afirmação sistêmica com uma eventual reprodução redundante de sua operação e que são responsáveis, igualmente, pela introdução de uma operação distinta no sistema. A decisão judicial causa interferência no sistema, afetando a sua redundância e, por conseguinte, pode gerar transformações estruturais no seu interior (desde que, repisa-se, tal variação seja tolerada ou selecionada pelas próprias estruturas e assimiladas como reestabilização).

Adverte Luhmann que

Não é por acaso que a concepção de uma "separação" entre Estado e a sociedade surge no momento em que o direito é positivado. O direito positivo é inevitavelmente um direito politicamente escolhido, "estatal". Seu destino está entrelaçado como o do sistema político na sociedade, pois só assim é possível obter-se uma grande variabilidade do direito, controlada por processos de seleção da própria sociedade. No entanto, isso não abre as portas para o livre arbítrio do estabelecimento puramente político do direito, e muito menos significa que o sistema político poderia decidir livremente sobre questões jurídicas, por si só e como se não possuísse um meio ambiente; aponta-se tão-somente para o caminho da procura das condições e das limitações estruturais da seleção do direito ${ }^{82}$.

Importante ressaltar, por oportuno, que, a partir de uma abordagem do campo da filosofia política do Garantismo, podem-se identificar - a partir da linguagem sistêmica - concepções autopoiéticas e heteropoiéticas, que tratam da legitimação do sistema jurídico no seio da teoria garantista.

Nas concepções autopoiéticas, o Estado é um fim em si mesmo e sua conservação e reforço devem ser instrumentalizados pelo Direito, su-

${ }_{82}$ LUHMANN, 1985, p. 44-45. 
bordinando-se a ele tanto os indivíduos como a sociedade, a partir de um ponto de vista interno ${ }^{83}$.

Já para as concepções heteropoiéticas, o Estado é um meio, legitimado unicamente pelo fim de garantir os direitos fundamentais do cidadão, e politicamente ilegítimo se não os garante, ou pior, se ele mesmo os viola. Assim, defende-se que a legitimação política do Direito e do Estado provém do externo ou de sua base, isto é, da sociedade, entendida como soma heterogênea de pessoas, de forças e de grupos sociais.

Dessa maneira, o Estado de Direito é caracterizado como um modelo de ordenamento justificado ou fundamentado por fins externos, geralmente declarados sob forma normativa, por suas Constituições, mas de modo incompleta. Como o subsistema jurídico adveio do sistema social, tem a sua base fundamentada neste. Contudo, diferenciou-se estruturalmente e, assim, emoldurou-se autonomamente como sistema, podendo, assim, fechar-se operacionalmente e abrir-se somente à cognição de seu ambiente em interferências toleráveis pela sua estrutura.

Nesse debate acerca da formação das estruturas normativas e da necessidade de sistematização do Direito, Luhmann afirma que não se pode discernir, exatamente, nenhuma causa motora:

Aqui deve bastar a constatação de que a mudança estrutural social, por maior que seja a suposição de que envolva "progresso", não representa nenhuma pedra de toque para a fundamentação da Teoria do Direito (só em nosso século chegaram os Juristas à ideia de fundamentar suas decisões em suas consequências, isto é ter que fundamentá-las a partir do futuro - justamente pela falta de confiança existente no futuro). O que se pode, efetivamente, observar confirma também essa incapacidade de fundamentação teórico-social do Direito. O Direito tem que ajudar-se a si mesmo $[\ldots]^{84}$.

Por isso, em que pese seus fins serem externos, a sua heteropoiese é base para debates filosófico-políticos, e não para a operacionalidade do sistema jurídico.

83 CADEMARTORI, Op. Cit., p. 162.

${ }^{84}$ LUHMANN, 2000, p. 153-161. 
Conclui-se, então, que a teoria jurídica que mais se aproxima do objetivo de promover a coerência de integralidade e incolumidade do sistema jurídico é a teoria Garantista, visto que não se utiliza de referências externas ao sistema jurídico, ou seja, não se pauta em outros códigos que lhe são distintos, ao contrário do que defendem as teorias Neoconstitucionalistas, propondo o entrelaçamento do Direito com a Moral e a Política, e outros métodos inominados de (des)construção do sistema jurídico que nele inserem critérios de toda ordem, tais como os de fins socioeconômicos.

\section{Conclusões}

Com respeito à teoria luhmanniana, a comunicação do sistema social, a partir do problema da ordem social, passou a desenvolver a seletividade de determinadas relações operacionais que representavam as expectativas dos indivíduos de seu meio, razão pela qual tal operacionalidade distinguiu-se do ambiente e institucionalizou, dentre os valores defendidos por tais indivíduos, os interesses que pudessem ser considerados de extrema relevância social. Sem adentrar às discussões que envolvem tal mutação, tem-se um processo de diferenciação funcional entre tais interesses que representou a evolução do sistema social: a formação do Direito, subsistema jurídico, autônomo do subsistema moral.

O Direito, por sua vez, evoluiu, no sentido de incremento de sofisticação de mecanismos operacionais, até se constituir em um subsistema social autopoiético, composto de comunicações de elementos normativos, cuja validade é tida pela recursividade entre estes.

Em sua autonomia, o sistema jurídico autolegitima-se em seus próprios elementos normativos e, por essa razão, no dizer de Luhmann, não são os indivíduos que fundam a ordem social (por meio do contrato social), mas é essa ordem que fundamenta os indivíduos. Dessa forma é possível questionar a visão contratualista clássica, perguntando: quem conclui esse contrato? e perquirir quais são os "atributos naturais" (interesse, impulsos, direitos naturais) que formam a base das vantagens dos contratantes? 
Os motivos dessas vantagens causam a alopoiese social do direito: a prevalência de outros códigos de preferência sobre o código direito/não-direito distorce a definição clara das fronteiras de uma esfera de juridicidade, o que implica privilégios e exclusões ilegais, seja com a juridificação de critérios de "não-direito", seja com a desjuridificação do que está institucionalizado.

Permitir a interferência de códigos alienígenas na formação e ressonância das decisões judiciais significa não só obstar a evolução do Direito e, por conseguinte, da sociedade, como, igualmente, promover a regressão de seu movimento sistêmico e não confiar em seus elementos normativos atuais, já que o debate acerca de um utópico dever ser revela a incredibilidade do direito posto e vigente. Tal contexto, agregado à hipercomplexidade social e à ausência de uma moral única à sociedade, ocasiona o enfraquecimento do sistema jurídico, o qual, progressivamente, remanesce à mercê dos interesses defendidos por outros códigos, além de propagar a sua ausência de credibilidade.

Não se pode aceitar, portanto, que a abertura cognitiva do sistema jurídico se preste à satisfação das exigências econômicas, morais ou de quaisquer outras ordens presentes na esfera pública, bem como que o fechamento operacional permita a reprodução de critérios não-jurídicos dentro do Direito.

Como óbice a essa colonização do sistema jurídico pelo sistema social, e visando uma configuração sistêmica própria do Direito, deve-se superar as condições desjuridicizantes que a determinam. É imprescindível, portanto, que a decisão judicial - operação comunicativa jurídica por excelência - mantenha incólume a formatação da estrutura sistêmica do Direito, de modo que reflita a sua abertura cognitiva, respeitando a sua integridade (heterorreferência), e ordene o seu fechamento operacional, impedindo que elementos externos do ambiente condicionem ou induzam o seu resultado.

Abandonam-se, aqui, as possibilidades de entrelaçamento entre o sistema jurídico com a Moral e/ou Política, o que é defendido pelo Neoconstitucionalismo, e abriga-se a concepção de que o aspecto normativo da decisão judicial deve pretender à sua generalização porque o órgão 
jurisdicional submete-se ao princípio da igualdade de forma diferente do legislador. É dever do julgador tanto tratar sob critérios iguais as mesmas circunstâncias quanto decidir da mesma forma os casos similares, o que torna questionável a concepção do ato decisório como "a lei do caso particular".

Nesse ponto, a Teoria do Garantismo propõe uma aceitável base teórica à operacionalidade do Direito. Considerando que Estado Constitucional incorporou diversos princípios ético-políticos a seus estatutos fundamentais, tornando-os critérios internos de legitimidade, fortaleceu o princípio da legalidade com a atenção voltada ao Direito positivo vigente, orientada a analisar os aspectos de sua ineficácia e invalidade. Por isso, obsta-se a crítica externa, cujo debate abrange critérios políticos ou de justiça.

Portanto, é inconcebível a perquirição acerca do consenso do Direito com a Justiça ou com a Política (o que representa o exame do sistema jurídico a partir de um ponto de vista externo), pois caracterizaria uma desconstrução do Estado de Direito. Essa tarefa fica a cargo da filosofia política ou jurídica e não da operação comunicativo-recursiva por excelência do Direito, que é a decisão judicial.

\section{Referências}

AMADO, Juan Antonio Garcia. A sociedade e o direito na obra de Niklas Luhmann. In: ARNALD, André-Jean; LOPES JUNIOR, Dalmir. Niklas Luhmann: do sistema social à sociedade jurídica. Rio de Janeiro: Lumen Juris, 2004.

CADEMARTORI, Luiz Henrique Urquhart; DUARTE, Francisco Carlos. Hermenêutica e Argumentação Constitucional. São Paulo: Atlas, 2009.

CADEMARTORI, Sérgio. Estado de direito e legitimidade: uma abordagem garantista. Porto Alegre: Livraria do Advogado, 1999.

CARVALHO, Salo. Pena e garantias: uma leitura do garantismo de Luigi Ferrajoli no Brasil. Rio de Janeiro: Lumen Juris, 2001. p. 100-101. 
FEBBRAJO, Alberto. Introduzione all'edizione italiana. In: LUHMANN, Niklas. Sistemi sociali: Fundamenti di una teoria generale. Tradução italiana: Alberto Febbrajo e Reinhard Schimidt. Bologna: Il Mulino, 1990.

FERRAJOLI, Luigi. Derecho y razón. Madrid: Trotta, 2001.

. Garantismo: debate sobre el derecho y la democracia. Madrid:

Trotta, 2006.

KUNZLER, Caroline de Morais. A teoria dos sistemas de Niklas

Luhmann. Estudo de Sociologia, Araraquara, n. 16. p. 123-136, 2004.

LUHMANN, Niklas; DE GIORGI, Raffaele. Teoria della Società. 6. ed. Milano: Franco Angeli, 1994.

LUHMANN, Niklas. El derecho de la sociedad. 2. ed. Ciudad del México: Herder; Universidad Iberoamericana, 2005.

. La religión de la sociedad. Madrid: Trota, 2007.

. O paradoxo dos direitos humanos e três formas de seu desdobramento. Traduzido por Ricardo Henrique Arruda de Paula e Paulo Antônio de Menezes Albuquerque. Themis, Fortaleza, v. 3, n. 1, p. 153-161, 2000.

. Sociologia do direito I. Rio de Janeiro: Tempo Brasileiro, 1983.

1985. . Sociologia do direito II. Rio de Janeiro, Tempo Brasileiro,

MADEIRA, Lígia Mori. O direito nas teorias sociológicas de Pierre Bourdieu e Niklas Luhmann. Direito \& Justiça, Porto Alegre, v. 33, n. 1, p. 19-39, jun. 2007.

NEVES, Clarissa Baeta; SAMIOS, Eva Machado B. Niklas Luhmann: A Nova Teoria dos Sistemas. Porto Alegre: Goethe Institut,1997.

NEVES, Marcelo. Entre Têmis e Leviatã: uma relação difícil: o estado democrático de direito a partir e além de Luhmann e Habermas. São Paulo: Martins Fontes, 2006. 
SANCHÍS, Luis Prieto. Neoconstitucionalismo y ponderación judicial. In: CARBONELL, Miguel (Org.). Neoconstitucionalismo(s). Madrid: Trotta, 2003.

SILVA, Virgilio Afonso da. O proporcional e o razoável. Revista dos Tribunais, n. 798, p. 23-50, 2002.

SIMIONI, Rafael Lazzarotto; BAHIA, Alexandre Gustavo Melo Franco. Como os juízes decidem? Proximidades e divergências entre as teorias da decisão de Jürgen Habermas e Niklas Luhmann. Revista Seqüência, Florianópolis, n. 59, p. 61-88, dez. 2009. 